\title{
Nutrient intake, nutrient status and pattern of infections in HIV sero-positive patients in Chulaimbo Sub-district hospital, Kenya
}

\author{
Agatha Christine Onyango ${ }^{1,}$, Mary Khakoni Walingo ${ }^{1}$, Grace Mbagaya ${ }^{2}$, Rose Kakai ${ }^{3}$ \\ ${ }^{1}$ Department of Nutrition and Health School of Public Health and Community Development, Maseno University, Private Bag-40100 \\ Maseno, Kenya \\ ${ }^{2}$ Department of Family and Consumer Sciences, School of Agriculture and Biotechnology, Moi University, Eldoret, Kenya \\ ${ }^{3}$ Department of Biomedical Sciences and Technology, School of Public Health and Community Development, Maseno University, \\ Private Bag-40100 Maseno, Kenya
}

\section{Email address:}

acatieno@yahoo.com (A. C. Onyango), marywalingo@yahoo.com(M. K. Walingo), mbagaya@gmail.com (G. Mbagaya), kakairose@yahoo.com (R. Kakai)

\section{To cite this article:}

Agatha Christine Onyango, Mary Khakoni Walingo, Grace Mbagaya, Rose Kakai. Nutrient Intake, Nutrient Status and Pattern of Infections in HIV Sero-Positive Patients in Chulaimbo Sub-District Hospital, Kenya. Journal of Food and Nutrition Sciences. Vol. 2, No. 4, 2014, pp. 117-123. doi: 10.11648/j.jfns.20140204.14

\begin{abstract}
HIV worsens the nutritional status by increasing the body's requirement for food and also leads to opportunistic infections, which in turn, increase body nutrition requirements. The objective was to assess nutrient intake, nutrient status and nutritional status and establish the infection pattern of HIV seropositive patients attending a Comprehensive Care Clinic. A prospective cohort design was adopted where 497 HIV and AIDS patients enrolled at the hospital were followed for six months. This comprised of 105 males and 392 females attending the AMPATH Comprehensive Care Clinic in Chulaimbo Sub-district hospital from February 2010 to July 2010. Analysis of nutrient intake using 24-hour recall, food frequency checklist, nutrient status using biochemical assessment indicators (haemoglobin, creatinine, serum glutamate pyruvate (SGPT) and mean corpuscular volume (MCV) and pattern of infections using a morbidity tool. There was inadequate nutrient intake reported in most of the patients although a slightly more than half (55.3\%) had three meals per day. Malnutrition was observed in 20.3\% of 497 HIV sero-positive patients were who had a mean BMI $<18.5 \mathrm{~kg} / \mathrm{m}^{2}$. The common co-infections/opportunistic infections were pneumonia $(16.1 \%)$, tuberculosis $(14.9 \%)$, dermatitis $(8.7 \%)$, malaria $(5.6 \%)$ and oral candidiasis $(0.8 \%)$. Therefore, nutrition assessment of HIV and AIDS patients is important at all stages of the disease in order to identify those with signs of malnutrition. This will assist in preventing or detecting malnutrition from the early stages of HIV infection among HIV and AIDS patients.
\end{abstract}

Keywords: Infections, Nutrient Intake, Human Immunodeficiency Virus, AIDS, Nutrient Status, Malnutrition

\section{Introduction}

Good nutrition is vital for health, and the immune function is affected with inadequate nutrient intake and this could lead to infections. In disease states like HIV infection inadequate nutrient intake and micronutrients can have an adverse effect on the immune function. When macronutrient intake is insufficient to meet metabolic needs, protein-calorie malnutrition (PCM) and deficiencies of micronutrients develop (1). These deficiencies impair both the synthesis of molecules necessary for the immune response and the function of immune-related enzyme systems (2). When this impairment occurs the individual is predisposed to opportunistic infections. In HIV disease, the presence of malnutrition strongly predicts patient survival independent of CD4 (Cluster of Differentiation) Tlymphocyte counts (2). Clinical deficiencies of some nutrients occur rapidly in response to dietary deficiencies, malabsorption, or altered metabolism, while those having a storage form in the body may take longer. Malnutrition alters the immune function with increase in susceptibility to infections, faster disease progression, reduced functional status, quality of life, and increased morbidity and mortality (3).The presenting symptoms of malnutrition typically include weight loss, a change in body habitus (loss of lean 
body mass) or a change in functional status (inability to perform daily activities) (1).

Infections affect the nutritional status of an individual suffering from HIV and AIDS in various ways. The pathogenesis of nutritional impairment in HIV-positive patients is multifaceted and includes decreased food intake, decreased nutrient absorption and decreased efficiency of utilization, in addition to increased nutritional demand (4). HIV infection accelerates the release of pro-oxidants, cytokines and other reactive oxygen species, leading to increased utilization of antioxidants such as vitamin E, C, beta-carotene and micronutrients e.g. iron, zinc, selenium, manganese and copper (5). An imbalance between these pro-oxidants and antioxidants causes oxidative stress which further damages the immune cells, proteins and enzymes, thus accelerating HIV replication (3).

HIV and nutrition are intimately linked in that HIV infection can lead to malnutrition, while poor diet can in turn speed disease progress. AIDS is characterized by progressive depletion of a specific group of immune cells called (CD4+) helper $\mathrm{T}$ lymphocytes whose loss leads to opportunistic infections and cancer (1). Micronutrients play an important role in building cellular structures, generating biological energy and acting as biocatalysts of multiple enzymatic processes in the body. Macro-and micronutrient deficiencies could impair host immune functions and promote viral replication and pathogenicity, thus potentially affecting the clinical course of HIV infection (2).Micronutrient deficiency and infections are mutually aggravating, as infections can turn marginal micronutrient deficiencies into severe conditions, and vice versa (5). Vitamins A, C, B-group, D and E support the production of white blood cells, as well as various cytokines and cellular modulators of immunity, including antibody production (5). Among other important biological factors impacting on immunity at cellular and organ levels are availability of minerals, such as iron, copper, magnesium, selenium and zinc, (2).

\section{Materials and Methods}

This study was carried out at Chulaimbo Sub-district hospital which is situated in Kisumu West District in Nyanza Province, Kenya. The study adopted a prospective cohort research design with the sampling unit being an adult patient either female or male aged 18 to 60 years attending the Academic Models for the Prevention and Treatment of HIV and AIDS (AMPATH) clinic. Of the 497 HIV sero-positive patients recruited for the study, 493 completed the study. Two of the patients were transferred to other clinics, one declined to continue and one died. The study was performed two days a week, the days being selected from a table of random numbers. Patients requiring hospitalization were excluded. Each patient was recruited once on the first visit and followed for six months. A standardized interview schedule was used to collect morbidity, demographic and socio-economic information of the patients. The interview schedule consisted of both openended and closed-ended questions. This tool was administered by the research assistants with the help of the clinicians and researcher. Diet variety was assessed using a food frequency checklist once at the start of the study and nutrient intake using 24-hour dietary recall and a morbidity survey tool was used to collect information on the types and the rate of infections of the patients every month for six months. Creatinine, haemoglobin, Serum glutamate pyruvate transaminase (SGPT) and mean corpuscular volume (MCV) measures were used to assess the nutrient status of the patients at the start of the study and at the end of the study. Ethical clearance was obtained from Institutional Ethics Research Committee, Moi University Teaching Hospital (FAN: IREC 000470). The researcher also sought informed consent from the patients and who were briefed on the research procedures and assured of confidentiality. The analysis of the nutrient value of the foods consumed within 24 hours was done by the use of the food composition tables by Sehmi (6). A value of over $100 \%$ was considered as above RDA nutrient consumption, whereas those consuming $90 \%-100 \%$ was considered optimum nutrient consumption and those consuming $<90 \%$ considered as below RDA nutrient consumption, this was obtained by dividing he total nutrient intake by the RDA multiplied by $100 \%$ (Onyango et al.,(7). Statistical analysis was performed using the Chi-square test and $t$-test. Analyses were conducted using SPSS version 16 . Differences were considered significant if $P<0.05$.

\section{Results}

Morbidity and infections were studied in terms of sex and there were no differences in prevalence of morbidity. Those who experienced illnesses were 229 (46.1\%), pneumonia $80(16.1 \%)$, and tuberculosis $74(14.9 \%)$ and diarrhoea $188(37.8 \%)$ were the most prevalent infections, as illustrated in Table 1 . The males $46(43.8 \%)$ had higher prevalence of diarrhoea compared to the females 142 $(36.2 \%)$.

Table 1. Distribution of HIV Sero-positive Patients by Prevalence of Morbidity and Sex $n=497$

\begin{tabular}{llll}
\hline \multirow{2}{*}{ Characteristics } & Male & Female & Total \\
\cline { 2 - 4 } & No. (\%) & No. (\%) & No. (\%) \\
\hline Morbidity & $52(49.5 \%)$ & $177(45.2 \%)$ & $229(46.1 \%)$ \\
Experienced illness & $53(50.5 \%)$ & $215(54.8 \%)$ & $268(53.9 \%)$ \\
Not experience illness & $105(100 \%)$ & $392(100 \%)$ & $497(100 \%)$ \\
Total within morbidity & $105(21.1 \%)$ & $392(78.9 \%)$ & $497(100 \%)$ \\
Total within sex & & & \\
Type of infections & & & \\
\hline
\end{tabular}




\begin{tabular}{llll}
\hline \multirow{2}{*}{ Characteristics } & Male & Female & Total \\
\cline { 2 - 4 } & No. (\%) & No. (\%) & No. (\%) \\
\hline Pneumonia & $14(13.3 \%)$ & $66(16.8 \%)$ & $80(16.1 \%)$ \\
Tuberculosis & $21(20.0 \%)$ & $53(13.5 \%)$ & $74(14.9 \%)$ \\
Candidiasis & $1(1.0 \%)$ & $3(0.8 \%)$ & $4(0.8 \%)$ \\
Dermatitis & $9(8.6 \%)$ & $34(8.7 \%)$ & $43(8.7 \%)$ \\
Malaria & $7(6.6 \%)$ & $21(5.4 \%)$ & $28(5.6 \%)$ \\
Upper respiratory tract infections & $0(0.0 \%)$ & $0(0.0 \%)$ & $0(0.0 \%)$ \\
No infection & $53(50.5 \%)$ & $215(54.8 \%)$ & $268(53.9 \%)$ \\
Total within infections & $105(100 \%)$ & $392(100 \%)$ & $497(100 \%)$ \\
Total within sex & $105(21.1 \%)$ & $392(78.9 \%)$ & $497(100 \%)$ \\
Diarrhoea & & & $188(37.8 \%)$ \\
Suffered diarrhoea & $46(43.8 \%)$ & $142(36.2 \%)$ & $309(62.2 \%)$ \\
Not suffered & $59(56.2 \%)$ & $250(63.8 \%)$ & $497(100 \%)$ \\
Total within diarrhoea & $105(100 \%)$ & $392(100 \%)$ & $497(100 \%)$ \\
Total within sex & $105(21.1 \%)$ & $392(78.9 \%)$ & $8(1.6 \%)$ \\
Frequency of diarrhoea & & & $18(3.6 \%)$ \\
Daily & $1(1.0 \%)$ & $7(1.8 \%)$ & $17(3.4 \%)$ \\
Weekly & $4(3.8 \%)$ & $14(3.6 \%)$ & $145(29.2 \%)$ \\
Monthly & $5(4.8 \%)$ & $12(3.1 \%)$ & $309(62.2 \%)$ \\
Occasionally & $36(34.2 \%)$ & $109(27.8 \%)$ & $497(100 \%)$ \\
Not suffered diarrhoea & $59(56.2 \%)$ & $250(63.7 \%)$ & $497(100 \%)$ \\
Total within frequency of diarrhoea & $105(100 \%)$ & $392(100 \%)$ & $392(78.9 \%)$ \\
Total within sex & $105(21.1 \%)$ & & \\
\hline
\end{tabular}

Assessment of biochemical indicators was done twice at between the HIV patients who suffered from infections and the beginning and end of the study $(\mathrm{n}=495)$. There was no those who had not as shown in Table 2. significant difference in the mean nutrient status indicators

Table 2. Comparison of Mean Values of Nutrient Status Indicators by sex in HIV Patients

\begin{tabular}{lllll}
\hline Biochemical Assessment Indicator & Sex & N & Mean \pm (SD) & Normal range \\
\hline \multirow{2}{*}{ Haemoglobin $(\mathrm{g} / \mathrm{dL})$} & Male & 105 & $11.41( \pm 2.60)$ & $14-18$ \\
& Female & 392 & $11.19( \pm 4.25)$ & $12-16$ \\
Creatinine $(\mathrm{mg} / \mathrm{dL})$ & Male & 105 & $0.73( \pm 0.22)$ & $0.6-1.5$ \\
& Female & 392 & $0.60( \pm 19.14)$ & $0.6-1.5$ \\
SGPT(IU) & Male & 105 & $27.71( \pm 20.21)$ & $0-50$ \\
& Female & 392 & $24.06( \pm 18.78)$ & $0-50$ \\
MCV (femtoliters) & Male & 105 & $86.63( \pm 15.93)$ & $79-100$ \\
& Female & 392 & $84.61( \pm 14.51)$ & $79-100$ \\
\hline
\end{tabular}

Key: $* \alpha=0.05, \mathrm{SGPT}=$ Serum Glutamic Pyruvate Transaminase, $\mathrm{MCV}=$ Mean Corpuscular Volume

There was a significant difference in mean nutrient intake of niacin (t-test $=-2.93, \mathrm{df}=997.73, p=0.003)$ and

thiamine (t-test $=-2.032, \mathrm{df}=2881.64, p=0.042)$, being higher for non-infected patients as shown in Table 3.

Table 3. Comparison of Mean Values of Nutrient Intake against Infections in HIV Patients

\begin{tabular}{|c|c|c|c|c|c|c|}
\hline Nutrients & Infections & $\mathbf{N}$ & Mean $( \pm$ SD) & Normal Values & $\mathbf{t}$ & Sig \\
\hline \multirow{2}{*}{ Energy(kcal) } & Suffered infection & 1565 & $1608.06( \pm 858.86)$ & $2100-3000$ & -1.14 & 0.254 \\
\hline & Not suffered & 1399 & $1639.00( \pm 608.26)$ & & & \\
\hline \multirow{2}{*}{ Protein $(g)$} & Infected & 1565 & $39.50( \pm 11.94)$ & $46-56$ & -1.17 & 0.241 \\
\hline & Not infected & 1399 & $40.01( \pm 1.83)$ & & & \\
\hline \multirow{2}{*}{ Iron(mg) } & Infected & 1565 & $10.48( \pm 3.23)$ & $8-18$ & 0.25 & 0.802 \\
\hline & Not infected & 1399 & $10.45( \pm 3.20)$ & & & \\
\hline \multirow{2}{*}{ Calcium(mg) } & Infected & 1565 & $519.18( \pm 320.59)$ & 1200 & 0.32 & 0.747 \\
\hline & Not infected & 1399 & $515.40( \pm 317.20)$ & & & \\
\hline \multirow{2}{*}{ Vit A(IU) } & Infected & 1565 & $4805.64( \pm 5736.15)$ & 17000 & -0.10 & 0.919 \\
\hline & Not infected & 1399 & $4829.34( \pm 6787.31)$ & & & \\
\hline \multirow{2}{*}{ Vit C(mg) } & Infected & 1565 & $51.21( \pm 25.75)$ & $75-90$ & -1.55 & 0.121 \\
\hline & Not infected & 1399 & $52.66( \pm 25.11)$ & & & \\
\hline \multirow{2}{*}{ Thiamine(mg) } & Infected & 1565 & $1.68( \pm 0.67)$ & $1.1-1.2$ & -2.03 & $0.042 *$ \\
\hline & Not infected & 1399 & $1.73( \pm 0.71)$ & & & \\
\hline \multirow{2}{*}{ Riboflavin(mg) } & Infected & 1565 & $0.45( \pm 0.41)$ & $1.1-1.3$ & -0.32 & 0.751 \\
\hline & Not infected & 1399 & $0.45( \pm 0.40)$ & & & \\
\hline \multirow{2}{*}{$\operatorname{Niacin}(m g)$} & Infected & 1565 & $10.19( \pm 4.12)$ & $14-16$ & -2.93 & $0.003 *$ \\
\hline & Not infected & 1399 & $10.65( \pm 4.30)$ & & & \\
\hline
\end{tabular}

$*_{\alpha} \alpha=0.05$ 
Assessment of the episodes of diarrhoea was done twice at the beginning and end of the study for nutritional status indicators and immune status measures (305 episodes) and monthly for BMI and nutrient levels (922 episodes). There was no statistically significant difference in the nutrient intake between those suffered episodes of diarrhoea and those who did not in the mean values of nutritional status. Even as this was the case those who suffered episodes of diarrhoea had lower means compared to those who did not except the creatinine levels $(0.65 \pm 0.22)$ as shown in Table 4. There was a statistical significant difference in the mean nutrient intake of calcium $(495.11 \mathrm{mg}$ vs. $527.46 \mathrm{mg}$, $\mathrm{t}$-test $=$ -2.617 , df $=1877.48, p=0.009)$, thiamine $(1.64 \mathrm{mg}$ vs. $1.73 \mathrm{mg}$, t-test $=-3.345, \mathrm{df}=2006.35, p=0.001)$ and niacin $(10.16 \mathrm{mg}$ vs. $10.52 \mathrm{mg}, \mathrm{t}$-test $=-2.141, \mathrm{df}=1790.45, p=$ 0.032), as shown in Table 4.

Table 4. Comparison of Mean Values of Nutritional Status and Nutrient Intake across Episodes of Diarrhoea

\begin{tabular}{|c|c|c|c|c|c|c|}
\hline Characteristics & Health Status & Episode & Normal range & Mean ( \pm SD) & $\mathbf{t}$ & Sig \\
\hline \multicolumn{7}{|l|}{ Nutritional Status } \\
\hline \multirow[t]{2}{*}{ Haemoglobin (g/dL) } & Diarrhoea & 305 & $12-18$ & $11.02( \pm 2.31)$ & -1.01 & 0.315 \\
\hline & No diarrhoea & 685 & & $11.21( \pm 3.57)$ & & \\
\hline \multirow[t]{2}{*}{ Creatinine (mg/dL) } & Diarrhoea & 305 & $0.6-1.5$ & $0.65( \pm 0.22)$ & 1.74 & 0.082 \\
\hline & No diarrhoea & 685 & & $0.62( \pm 0.20)$ & & \\
\hline \multirow[t]{2}{*}{ SGPT (UI/L) } & Diarrhoea & 305 & $0-50$ & $24.45( \pm 17.42)$ & -0.39 & 0.696 \\
\hline & No diarrhoea & 685 & & $24.941( \pm 19.76)$ & & \\
\hline \multirow[t]{2}{*}{ MCV (femolitres) } & Diarrhoea & 305 & $79-100$ & $85.06( \pm 15.84)$ & 0.01 & 0.995 \\
\hline & Did not diarrhoea & 685 & & $85.05( \pm 15.84)$ & & \\
\hline \multicolumn{7}{|c|}{ BMI and Nutrient levels } \\
\hline \multirow[t]{2}{*}{ BMI $\left(\mathrm{kg} / \mathrm{m}^{2}\right)$} & Diarrhoea & 922 & $18.5-24.9$ & $21.06( \pm 5.03)$ & -2.19 & $0.029 *$ \\
\hline & No diarrhoea & 2042 & & $21.47( \pm 3.73)$ & & \\
\hline \multirow[t]{2}{*}{ Energy (kcal) } & Had diarrhoea & 922 & $2100-3000$ & $1612.04( \pm 985.94)$ & -0.448 & 0.662 \\
\hline & Did not diarrhoea & 2042 & & $1627.00( \pm 616.67)$ & & \\
\hline \multirow[t]{2}{*}{ Protein $(\mathrm{g})$} & Had diarrhoea & 922 & $46-56$ & $39.56( \pm 11.87)$ & -0.55 & 0.581 \\
\hline & Did not diarrhoea & 2042 & & $39.82( \pm 11.89)$ & & \\
\hline \multirow[t]{2}{*}{ Iron (mg) } & Had diarrhoea & 922 & $8-18$ & $10.42( \pm 3.17)$ & -0.57 & 0.571 \\
\hline & Did not diarrhoea & 2042 & & $10.49( \pm 3.24)$ & & \\
\hline \multirow[t]{2}{*}{ Calcium (mg) } & Had diarrhoea & 922 & 1200 & $495.11( \pm 305.55)$ & -2.62 & $0.009 *$ \\
\hline & Did not diarrhoea & 2042 & & $527.46( \pm 324.39)$ & & \\
\hline \multirow[t]{2}{*}{ Vitamin A (IU) } & Had diarrhoea & 922 & 17000 & $4586.38( \pm 5520.28)$ & -1.44 & 0.151 \\
\hline & Did not diarrhoea & 2042 & & $4920.87( \pm 6556.08)$ & & \\
\hline \multirow[t]{2}{*}{ Vitamin C (mg) } & Had diarrhoea & 922 & $75-90$ & $51.23( \pm 26.02)$ & -0.94 & 0.345 \\
\hline & Did not diarrhoea & 2042 & & $52.20( \pm 25.20)$ & & \\
\hline \multirow[t]{2}{*}{ Thiamine (mg) } & Had diarrhoea & 922 & $1.1-1.2$ & $1.64( \pm 0.63)$ & -3.35 & $0.001 *$ \\
\hline & Did not diarrhoea & 2042 & & $1.73( \pm 0.71)$ & & \\
\hline \multirow[t]{2}{*}{ Riboflavin (mg) } & Had diarrhoea & 922 & $1.1-1.3$ & $0.44( \pm 0.38)$ & -1.00 & 0.317 \\
\hline & Did not diarrhoea & 2042 & & $0.45( \pm 0.42)$ & & \\
\hline \multirow[t]{2}{*}{ Niacin (mg) } & Had diarrhoea & 922 & $14-16$ & $10.16( \pm 4.19)$ & -2.14 & $0.032 *$ \\
\hline & Did not diarrhoea & 2042 & & $10.52( \pm 4.22)$ & & \\
\hline
\end{tabular}

$* \alpha=0.05$

\section{Discussion}

Nutritional quality of the diet does improve with consumption of greater food diversity, (8); (10).Diet diversity has however widely been associated with high socio-economic status (9). This is because people with high income may have the economic ability to purchase different types of foods from different food groups whereas those with low income stick to the few cheaper foods available, and this limits diet diversification among the poor people (5). Monthly income can be a strong and significant predictor of diet diversity among HIV patients. Studies have shown that diet diversity correlates with nutrient adequacy. Hatløy et al., (10) and Slattery et al., (9) observed that nutritional quality of the diet does improve with consumption of greater food diversity. A study by Stewart, (11) reported that daily servings of the same food from each food source may not be enough, but that one should choose variety within food sources because the characteristic nutrients in each group vary greatly for individual foods.

The findings of this study showed that there was variety in the intake of foods from various food sources even though the amounts were not sufficient among the HIV sero-positive patients. This supports the findings of (5) in which a diversified diet contributed to resistance to opportunistic infections in AIDS patients. However it is generally understood that no food contains all necessary nutrients and that diversity in the diet is needed to ensure a balanced diet. This implies that diversified diets are likely to ensure nutrient adequacy, and individuals who diversify diets have a likelihood of having a good nutritional status. The most commonly consumed food sources were vegetables $(23.8 \%)$ and fats or oils $(49.6 \%)$. The foods consumed and the frequency of consumption determines an individual's food security status (17). Therefore if the food 
consumption and frequency is low the HIV-sero-positive patient becomes more food insecure.

There was inadequate food intake reported by most of the patients although majority $(55.3 \%)$ had three meals per day. In the month of June majority of the patients had two meals $(42.9 \%)$ ).Adequate diet is vital for the health and survival of all HIV-infected persons and this reduces immunosuppression. As observed in this study, the mean energy intake is lower than the RDA for both male and female patients. The patients may have been consuming a variety of carbohydrate sources (daily $15.5 \%$, weekly $13.7 \%$, occasionally $54.5 \%$ and not consuming $16.4 \%$ ) but not in adequate amounts to meet their dietary needs. This does not agree with findings as reported by Hogg et al., (12) that in a study in South Africa most HIV-infected patients had energy and protein intakes that met at least $67 \%$ of the recommended daily amount. However, most of these patients had indications of low intake of vitamins $C, A, D$ and $\mathrm{B}_{6}$ and of zinc, iron and calcium. This is probably due to their high consumption of carbohydrate sources like maize meal, which contains only low levels of these nutrients. The results in this study are consistent with findings by Onyango et al., (7) that only $48.3 \%$ met the RDA for energy among HIV sero-positive patients. Energy intake is related to the stage of the infection, rapid weight loss, anorexia, opportunistic infections, malabsorption and altered metabolism (14). Thus it is clear that HIV-infected patients are at increased nutritional risk. Both male and female patients had a mean protein intake of $41.65 \mathrm{~g}( \pm 15.67)$ and $39.23 \mathrm{~g}( \pm 11.89)$ lower than the RDA of $63 \mathrm{~g}$ and $50 \mathrm{~g}$. The results differ from the findings by Watson (1994), which reports a mean protein intake in HIV-positive patients that was higher than the RDA. Studies carried out on HIVinfected patients in the Free State province of South Africa and in Boston (USA) reported that a majority of the patients had a protein intake that met at least $67 \%$ of the RDA (15). The low intake of protein observed in this study may be associated with the patient's economic ability. There is the increased urinary nitrogen loss, increased protein utility, decreased skeletal protein synthesis and increased skeletal muscle breakdown reported in HIV-infected individuals as a result of this the low protein intake reported in this study may not compensate for the increased needs.

In this study, the majority of patients had an inadequate or low intake of micronutrients that was $<90 \%$ or lower than the RDA. The study also established that the intake of calcium and vitamin A and riboflavin was less than RDA in both females and males. The female patients had higher intake of most of the nutrients compared to the males except iron intake. Studies have shown that some minerals/trace elements may be key factors in maintaining health despite human immunodeficiency virus infection and in reducing mortality. Values higher than the RDA were identified for thiamine (male 135.8\% and female 160\%) and iron in male $(128.8 \%)$ in this study population. Each of the mineral/trace elements examined in this study may contribute to the general well-being of HIV-infected persons. Calcium has been shown to reduce diarrhoea in HIV-positive/AIDS patients (16). In this study, the mean calcium intake in male patients was $487.57 \pm 306.15$ and in female patients it was $542.21 \pm 320.59$; both being lower than the RDA (1200mg). Therefore, the results obtained from this study tend to suggest that patients with a high dietary intake might be able to replace lost calcium and in turn reduce the burden of diarrhoea. Iron is essential for the formation and functioning of red blood cells, and vitamin $\mathrm{C}$ is known to promote the absorption of iron. In male patients, the iron intake $(10.49 \pm 3.49)$ was higher than the RDA, nonetheless the females had a lower intake as shown in Table 4. Iron is one of the micronutrients that is commonly deficient in HIV infection. Haemoglobin level $(11.405 \mathrm{mg} / \mathrm{dl}( \pm 2.60)$ in males and $11.185 \mathrm{mg} / \mathrm{dl}( \pm 4.25)$ in females) was determined in this study to verify its correlation with dietary intake. As mentioned earlier, the female population had an inadequate intake of iron as opposed to the male population. The reason for this discrepancy is not clear, but it may be related to the fact that iron is lacking in women's food due to a lack of knowledge, consuming foods/diets deficient in iron or because of extra demands during the menstrual cycle (women need extra iron until they pass the menopause stage).

Tang et al., (18) observed a slower progression of disease and reduced risk of mortality with an increased intake of riboflavin, thiamine and vitamin $\mathrm{C}$. Vitamin $\mathrm{C}$ has been found to affect immune function in several ways (19). It can stimulate the production of interferons; the protein that protect cells against viral attack. However, the dietary intake of vitamin $\mathrm{C}$ was below RDA among the patients in this study. There is evidence that increased intakes of vitamin $\mathrm{C}$ may help to reduce the risk of diseases associated with increased oxidative stress (19). It is therefore envisaged that the inadequate vitamin $\mathrm{C}$ intake reported among the patients in this study is not beneficial to the patients. Although, the greater percentage of patients in this study had a dietary intake of the thiamine higher than the RDA, it should be noted that even a mild state of deficiency of these vitamins could result in an altered immune function, especially in patients who are not on antiretroviral drugs. As HIV infection progresses, coupled with opportunistic infections and metabolic demand, HIVinfected individuals may be unable to meet their required nutritional needs. This may be due to decreased oral intake, decreased nutrient absorption, increased nutrient requirements and changes in metabolism and nutrient transport, which could steadily result in greater inadequacy of these vitamins.

The dietary intake of vitamin A in this study was lower than the RDA for most of the patients $(22.8 \%$ male and $26.7 \%$ female). Tang et al. (18) reported that $12 \%-19 \%$ of HIV-positive patients at various stages of HIV infection show vitamin A inadequacy that is more prevalent in women than in men. However this study established that the females had a higher intake of vitamin A compared to 
the males. Studies have shown that there is a relationship between the dietary intake of vitamin $\mathrm{A}$ and immune function (20). High dietary intake of vitamin A may be related to metabolic demand during the acute phase of HIV infection, or an increased dietary intake, while the low intake could probably be associated with a more rapid progression to AIDS (21). There were low levels of haemoglobin (males $11.41 \pm 2.60$ and females $11.19 \pm 4.25$ ) and creatinine, SGPT and MCV levels were at the cut off for majority of the female patients. When Haemoglobin measures are low, tissues may not be receiving enough oxygen, leading to poor healing and less efficient organ function.

HIV related malnutrition has several causes (22), including but not limited to a decrease in food intake, the effects of opportunistic infections (23), metabolic inefficiencies due to cytokine activity and diarrhoea. Malnutrition itself can induce immunodepression and worsen HIV-related immunodepression (24). Once HIV has weakened the immune system, various infections can take hold, some of which can affect appetite and ability to eat (25).

Tuberculosis (TB) has been associated with malnutrition in HIV patients (26). HIV patients have an increased risk of developing TB because they have weakened immune systems. Host resistance to TB is dependent on cell mediated immune response, which is compromised in HIV positive individuals. One study found that HIV replicates faster when tuberculosis is also present (27). Infections may affect the nutritional status of an individual suffering from HIV and AIDS in various ways, such as a reduction in food intake and nutrient absorption and by increasing the utilization and excretion of proteins and micronutrients (28). This study established that $31 \%$ of the patients either suffered from pneumonia or tuberculosis as shown in Table 4. The patients also had respiratory tract infections especially from the month of April to July and this may be attributed to the cold season at this time of the year in Kenya.

Diarrhoea is one of the major infections among HIV patients and is well recognized as an important component of HIV related morbidity. Majority of the HIV sero-positive patients in this study were at an advanced stage of HIV disease (AIDS) as confirmed by clinical staging and CD4 level (26). Diarrhoea was experienced by over $50 \%$ of AIDS patients at some time during the course of their illness. It is an important cause of morbidity and mortality in up to a quarter of all HIV sero-positive patients (28). Diarrhoea is the most common Gastrointestinal (GI) symptom in patients with HIV. In this study $37.8 \%$ of the patients had some episode of diarrhoea and of these $29.2 \%$ had episodes of diarrhoea occasionally. Diarrhoea was most strongly associated with low nutrient intake especially calcium which is known to reduce the burden of diarrhoea in HIV infection. The worst hit month in the study was June with 59.6\% suffering various infections, with malaria $(21.1 \%)$ having the highest frequency.

\section{Conclusion}

An adequate, well balanced diet, providing required foods and consequently adequate nutrients meets the increased requirements of HIV infection/AIDS. High dietary intake of major macronutrients and micronutrients will help in maintaining the nutritional status and in reducing wasting in the HIV patients. It is therefore recommended that adequate dietary intake and nutrient supplementation should be encouraged in HIV infection to improve both survival and quality of life.

\section{Acknowledgements}

This study was made possible by Maseno University through provision of the facilities for the research. The respondents are also highly appreciated for their participation in this study. The authors' would like to thank the AMPATH clinic staff in-charge at Chulaimbo Sub-District Hospital and all the participants in the study. Above all, thanks to God Almighty for sufficient grace and strength.

\section{References}

[1] Baum, M. K., \& Shor-Posner, G. (1998). Micronutrient Status in Relationship to Mortality in HIV-1 Disease. Nutrition Reviews, 56 (1), S135-S139.

[2] Friis, H. (2006). Micronutrient interventions and HIV infection: A Review of Current Evidence Interventions aux Micronutriments dans l'infection VIH: Une Revue de l'évidence Courante Intervenciones Con Micronutrientes e Infección Por VIH: Una Revisión de la Evidencia Actual. Tropical Medicine \& International Health, 11 (12), 1849-1857.

[3] Schwarz, K. B. (1996). Oxidative Stress during Viral Infection: A Review, Free Radical Biology and Medicine, 5, 641-649.

[4] Semba, R. D., \& Tang, A. M. (1999). Micronutrients and the Pathogenesis of Human Immunodeficiency Virus Infection. British Journal of Nutrition, 81, 181-189.

[5] Friis, H., \& Michaelsen, K. F. (1998). Micronutrients in HIV Infection: A Review. European Journal of Clinical Nutrition, 52, 157-163.

[6] Sehmi, J. R. (1993). National Food Composition Tables and the Planning of Satisfactory Diets in Kenya. Nairobi, Kenya: Government Printer.

[7] Onyango, A. C., Walingo, M. K., \& Othuon, L. (2009). Food Consumption Patterns, Diversity of Food Nutrients and Mean Nutrient Intake in Relation to HIV/AIDS Status in Kisumu District Kenya. African Journal of AIDS Research, 8 (3), 371-379.

[8] Shimbo, S., Kimura, K., Imai, Y., Yasumoto, K., Yamamoto, K., Yamamoto, S., T., et al. (1994). Number of Food Items as an Indicator of Nutrient Intake. Ecology of Food and Nutrition, 32, 197-206.

[9] Slattery, M., Berry, T., J., P., \& Caan, B. (1997). Diet Diversity, Diet Composition and Risk of Colon Cancer. Cancer Causes and Control, 8, 872-882. 
[10] Hatløy, A., Torheim, L. E., \& Oshaug A. (1998). Food Variety - A Good Indicator of Nutritional Adequacy of the Diet? A Case Study from an Urban Area in Mali, West Africa. European Journal of Clinical Nutrition, 52, 891-898.

[11] Stewart, T. (2003). ABC of Nutrition. (Third Edition Ed.): Book AID International.

[12] Hogg, R. S., Zadra, J. N., \& Chan-Yan, C. (1995). Analysis of Nutritional Intake in a Cohort of Homosexual Men. Journal of Acquired Immune Deficiency Syndrome \& Human Retrovirology, 9, 162-167.

[13] Dworkin, B., Wormser., G. P., \& Rosenthal, W. S. (1985). Gastrointestinal Manifestations of the Acquired Immunodeficiency Syndrome: A Review of 22 Cases. American Journal of Gastroenterology, 80, 774-778.

[14] Dannhauser, A., Van Staden, A. M., \& Van der Ryst, E. (1999). Nutritional Status of HIV-1 Sero-positive Patients in the Free State Province of South Africa: Anthropometric and Dietary Profile. European Journal of Clinical Nutrition, 53, 165-173.

[15] Watson, R. R. (1994). Nutrition and AIDS. CRC Oress, Boca Raton, London: 120-130.

[16] Macallan, D. C., Noble, C., Baldwin, C., Foskett, M., McManus, T., \& Griffin, G. E. (1993). Prospective Analysis of Patterns of Weight Change in Stage IV Human Immunodeficiency Virus Infection. American Journal of Clinical Nutrition, 58, 417-424.

[17] Kotler, D. P. (2000). Body Composition Studies in HIVinfected Individuals. Anne Academy of Science, 904, 546552.

[18] Tang, A. M., Graham, N. M., Kirby, A. J., McCall, L. D., Willett, W. C., \& Saab A.J. (1993). Dietary Micronutrient Intake and Risk of Progression to AIDS in HIV-Infected Homosexual Men. Amercian Journal of Epidemiology, 138, 937-951.

[19] Macallan, D. C. (1999). Nutrition and Immune Function in Human Immunodeficiency Virus Infection. Paper Presented at the Proceedings of the Nutrition Society.
[20] Lefrancois, L. (1991). Intraepithelial Lymphocytes of the Intestinal Mucosa: Curiouser and Curiouser.Seminar of Immunology, 3 (2), 99-108.

[21] Raiten, D. J. (1991). Nutrition and HIV Ifection: A Review and Evaluation of the Extant Knowledge on the Relationship between Nutrition and HIV Infection. Nutrition Clinical. Practice, 6 Suppl (1), 1S:94S.

[22] Niyongabo, T., Melchior, J. C., Henzel, D., Bouchaud, O., \& Larouze, B. (1999). Comparison of Methods for Assessing Nutritional Status in HIV-infected Adults. Nutrition, 15, 740-743.

[23] De Cock, K. M., Soro, B., Coulibaly, I. M., \& Lucas, S. B. (1992). Tuberculosis and HIV Infection in Sub-saharan Africa. JAMA: The Journal of the American Medical Association, 268 (12), 1581-1587.

[24] Kant, A., Schatzkin, A., \& Ziegler R.G. (1995). Dietary Diversity and Subsequent Cause-specific Mortality in the Nhanes I Epidemiologic Follow-up Study. Journal of the American College of Nutrition, 14, 233-238.

[25] Hammond, K., A. (2004). Dietary and Clinical Assessment (11th Ed. Vol. 372). Philadelphia: WB Saunders Co: 372.

[26] Semba, R. D., \& Tang, A. M. (1999). Micronutrients and the Pathogenesis of Human Immunodeficiency Virus Infection. British Journal of Nutrition, 81, 181-189.

[27] Suresh, V. S. A., Gulati, A. K., Singh, V. P., Varma, V. D., Rai, M., \& S., S. (2006). Diarrhea, CD4 Counts and Enteric Infections in a Hospital - Based Cohort of HIV-infected Patients around Varanasi, India. BMC Infectious Diseases, 6 (39).

[28] Sande, M. A., \& Volberding, P. A. (1997). The Medical Management of AIDS (5th Ed. Vol. 185). Philadelphia: W.B. Saunders Company. 